\title{
EFFECT OF NANOPARTICLES MODIFIED GLASS IONOMER CEMENT ON THE COLOUR AND SHEAR BOND STRENGTH OF LITHIUM DISILICATE CERAMIC
}

\author{
Shereen Kotb Salem* and Rasha Sayed Asaad**
}

\begin{abstract}
The effect of glass ionomer cement modified by nanoparticles on the bond strength and colour of lithium disilicate ceramic was studied. Glass ionomer cement modified by nanosilver or nanogold, glass ionomer cement and IPS e.max CAD A2 were used. Thirty e.max CAD discs were constructed. The samples were divided into 3 groups, the first group, 10 samples (control group) used non modified glass ionomer cement (GIC), the second and third groups, 10 samples each used modified glass ionomer cement : nano silver (NSGIC), nanogold (NGGIC). The samples were then subdivided according to the test to which they will be subjected: colour test - shear bond strength test (5 samples each).The samples subjected to colour test were cemented to a composite discs with a shade A 2 while those subjected to shear bond strength test were cemented to dentine, using the 3 tested types of glass ionomer.
\end{abstract}

Results showed that $\Delta \mathrm{E}$ of all the tested samples recorded values in the range of clinical acceptability. NGGIC group showed less $\Delta \mathrm{E}$ than NSGIC group compared to the control group. Also, the results showed no statistical significant difference in shear bond strength between the control group (GIC) and the two experimental groups (NSGIC) and (NGGIC).

Conclusion: The addition of nanoparticles to glass ionomer cement resulted in $\Delta \mathrm{E}$ within the clinical acceptance. Also, they showed no significant difference as regards to shear bond strength.

Key Words: Glass ionomer, silver, gold, nanoparticles, bond strength, colour

\section{INTRODUCTION}

Glass-ceramics have been successfully used in dentistry for the past 20 years. They can be machined with modern CAD/CAM equipment. (1) Lithium disilicate glass-ceramic IPS e.max CAD provides about 3 times the strength of other glass-ceramics. ${ }^{(2)}$ This ceramic material meets the esthetic requirements and represents an economic alternative to $\mathrm{ZrO}_{2}$-supported single tooth restorations. ${ }^{(3)}$ According to the manufacturer, it can be cemented by use of the adhesive, self-adhesive or conventional techniques. This later technique can be used with glass ionomer cement.

* Lecturer of Fixed Prosthodontics. Faculty of Dentistry, October 6 University

** Oral and Maxillofacial Prosthodontic Department, Faculty of Dentistry,King Abdulaziz University, Jeddah,

Kingdom of Saudi Arabia 
Prognosis of fixed partial dentures depends on several factors; cementation procedure is one of them. ${ }^{(4)}$ Dental cement must be biocompatible, act as a barrier against microleakage, and strong enough to resist functional forces over the restoration's lifetime. ${ }^{(5)}$ Various types of dental luting cements are available. Glass ionomer cement was originally known as ASPA (aluminosilicate polyacrylic acid), it possess the properties of releasing fluoride, translucency of dental silicate cement as well as the chemical bond of the of polycarboxylate cement to tooth. ${ }^{(6,7)}$ It is also known to inhibit demineralization and even may re-mineralize adjacent tooth structure. ${ }^{(8,9)}$ It has some drawbacks such as, early susceptibility to moisture contamination, low wear resistance, low tensile and compression strength. ${ }^{(10)}$ Several techniques were advocated to strengthen the glass ionomer such as the addition of a metal alloy or polymerizable resins as resin-modified glass ionomer cement (RMGI). ${ }^{(11)}$

Recently, nano-structured materials receive considerable attention due to their unique physical, chemical, biological properties and functionally because of their nano-scale size. Nanotechnology developed a toxicity-free synthesis of metal nanoparticles. ${ }^{(12)}$ Silver and gold nano metals possess inherent antibacterial effect. Silver nanoparticles showed good antibacterial efficacy against bacteria (Grampositive and Gram-negative), fungi, viruses and other eukaryotic microorganisms. ${ }^{(13,14)}$ Gold nano-particles are chemically stable, inert and biocompatible. They possess unique thermal, chemical, biological properties as well as electronic effects, enhancing nano-particles' surface reactivity. ${ }^{(15)}$

Tooth colour is a function of light reflection from the tooth surface whether it is enamel or ceramic, in addition to the redirected light from the substructure whether it is dentine and luting agent or metal. The redirected light is subjected to internal refraction and reflection. The redirected light performs internal refraction and reflection. ${ }^{(16,17)}$ Ceramics improve esthetics by allowing light transmission through the restoration and the underlying tooth structure. ${ }^{(18,19,20)}$ Dental literature showed that several factors influence the colour of the restorations; among them is the type of substructure. ${ }^{(21-26)}$ Also, several previous studies ${ }^{(24,27-32)}$ reported that the underlying tooth structure is a major factor that affects the ceramic restorations final shade.

Although, therapeutic effect of adding antibacterial nano-particles to glass ionomer cement is proven by many researchers ${ }^{(15,33-36)}$ yet they may result in some physical and mechanical changes ${ }^{(33,37)}$

Porenczuk et al (2016), ${ }^{(34)}$ compared the shear bond strength and failure modes for glass-ionomer cement modified by silver and gold nanoparticles with dentin. They found non-significant difference in shear bond strength to dentine in all groups.

El-Wassefy et al (2017), (33) studied the mechanical properties of glass ionomer cement integrated with silver nanoparticles. They found insignificant decrease in mechanical properties and increase in colour darkness when increasing nanoparticles concentration. They considered colour changes as a potential limitation.

Restoration success depends mainly on proper bonding to tooth structure. ${ }^{(38)}$ Cements should be selected according to the material and type of restoration used. ${ }^{(39)}$ There is a lot of controversy concerning the cementation of lithium disilicate, zirconia-based and full zirconia ceramic restorations. In 2014 Christensen ${ }^{(40)}$ reviewed that both; adhesive and luting cements are used with clinical success. Adhesive resin cements bond to both tooth structure and restoration. But, due to difficulty in removal of restorations cemented with adhesive resin cements as well as practitioners inevitably remove more tooth structure than needed to remove a bonded resin-cemented lithium disilicate restoration, (33) it appears that luting the lithium disilicate restorations with conventional resin modified glass ionomer or conventional glass ionomer cements to be an 
acceptable choice when there exists a retentive tooth preparation. It allows less traumatic crown removal when needed. However the use of resin cement is necessary in case of unretentive the tooth preparation. ${ }^{(41)}$

This research studies the effect of adding silver \& gold nanoparticles to glass ionomer cement in order to benefit from their antibacterial properties, on bond strength and shade colour of ceramic e.max CAD samples. The hypothesis is that this addition may affect the final shade colour result as well as the bond strength to dentine.

\section{MATERIALS AND METHODS}

\section{Factorial design:}

Thirty samples were constructed composed of e.max CAD ceramic cemented to dentine. The samples were divided into 3 groups, the first group, 10 samples (control group), cemented using non modified glass ionomer cement (GIC), the second and third groups, 10 samples each, cemented using modified glass ionomer cement: nano-silver (NSGIC), nano-gold (NGGIC). Each group was then subdivided into two subgroups according to the test to which the samples will be subjected to: colour test - shear bond strength test (5 samples each).

\section{Preparation of the experimental glass ionomer cement}

In this current study, a commercially available glass ionomer, Vivaglass ${ }^{\circledR}$ CEM (Ivoclar Vivadent AG, Schaan, Liechtenstein) was used as recommended by the e.max CAD manufacturer. It is a highly translucent self-curing glass ionomer cement supplied as powder and liquid. For the control group, the manufacturer liquid was used as it is. As stated by the manufacturer the liquid consists of $85 \%$ water \& $15 \%$ tartaric acid. For the experimental groups, the liquids were prepared as follows: $1.5 \mathrm{gm}$ of tartaric acid (DL-Tartaric acid; extra pure tartaric acid) was weighed to a precision of $0.001 \mathrm{gm}$ using a digital balance (Fischer
Scientific- Unz \& Co. Inc.,N.Y., USA) and placed in measuring tubes of $10 \mathrm{ml}$ size. Then nano-gold (Mesogold: Colloidal gold nano particles $2-4 \mathrm{~nm}$ in deionized water, concentration 20ppm) and nanosilver (Mesosilver:Colloidal silver nano particles $0.65 \mathrm{~nm}$ in deionized water, concentration 20ppm) colloidal solutions were added to their respective tubes. Mixing is done till complete dissolution of all particles. ${ }^{(35)}$ Now we have three mixing solutions for the three tested groups.

\section{Ceramic samples construction}

An extra hard type IV stone material "Dentona" which is recommended for CAD/CAM models, was vacuum mixed with the recommended water/ powder ratio, vibrated and poured inside split copper molds with the intended dimensions $(10 \mathrm{~mm}$ diameter, $1.5 \mathrm{~mm}$ thickness for the samples of both tests: colour and shear bond strength tests), placed on a clean, dry glass slab. Another glass slab was seated on the upper surface of the mold to get a smooth flat surface. After the stone model setting, the mold was split; the model was trimmed to be ready to be scanned. The disc model was mounted on the model holder and scanned. Then, the sample was designed and milled from IPS e-max CAD LT blocks with colour shade A2. Finally, the samples were subjected to crystallization \& glaze firing with IPS e-max CAD Crystal/glaze paste. The IPS e.max CAD samples now reached their final physical and aesthetic properties, such as colour, translucency and brightness.

\section{Colour Test}

\section{Background preparation for the colour samples}

In order to standardize the substructure shade colour, 15 composite discs "(Z100 MP, 3M-ESPEAG, Seefeld, Germany)" with a shade A2, were constructed. ${ }^{(42)}$ The discs were made using the same split copper mold used for construction of the IPS e.max CAD discs for the colour samples. 


\section{Cementation procedures for the colour test samples:}

For the three types of glass ionomer cements used in this study (GIC, NSGIC, NGGIC), the mixing ratio between powder and liquid was $1: 1$ as recommended by the manufacturer. The composite surfaces of the tested samples were ultrasonically cleaned in 96\% alcohol for 2 minutes. Then the mixed cement was applied on the ceramic surface and finally seated on the composite disc. The excess cement was removed with sharp scaler and a protective varnish (Cervitec. Ivoclar Vivadent AG, Schaan, Liechtenstein) was applied. After storage period for 24 hours in distilled water, all the samples were subjected to thermocycling in a thermocycling machine (Proto-tech, Portland, Ore., USA) for 5000 cycles in water baths at 5 and $55^{\circ} \mathrm{C}$ with 30 seconds dwell time. ${ }^{(43)}$

\section{Colour Measurement Test}

CIELAB colour parameters were calculated from spectral reflectance measurements on a scanning spectrophotometer (VITA Easyshade Advance 4.0, Vita Zahnfabrick, Bad Säckingen, Germany). Scanning of the samples was performed over the visible spectrum $380-780 \mathrm{~nm}$. The CIELAB colour order system used in this research quantifies the sample colour by expressing it in terms of 3 coordinate values $(\mathrm{L}, \mathrm{a}, \mathrm{b})$ which locates the object in a 3-dimensional colour space.

The effect of nanoparticles addition to glass ionomer was assessed by determining the colour difference $(\Delta \mathrm{E})$ between CIELAB coordinates between the control group (GIC) and the two nano particles modified glass ionomer subgroups: nano-silver (NSGIC), nano-gold (NGGIC). Colour difference between the samples was calculated using the following formula:

$$
\Delta \mathrm{E}\left(\mathrm{L}^{*}, \mathrm{a}^{*}, \mathrm{~b}^{*}\right)=\left(\left[\Delta \mathrm{L}^{*}\right]^{2}+\left[\Delta \mathrm{a}^{*}\right]^{2}+\left[\Delta \mathrm{b}^{*}\right]^{2}\right)^{1 / 2(44)}
$$

where

$\Delta \mathrm{L}^{*}=\mathrm{L}$ of the control group $-\mathrm{L}$ of the nanoparticles glass ionomer subgroup

$\Delta \mathrm{a}^{*}=\mathrm{a}$ of the control group $-\mathrm{a}$ of the nanoparticles glass ionomer subgroup

$\Delta \mathrm{b}^{*}=\mathrm{b}$ of the control group $-\mathrm{b}$ of the nanoparticles glass ionomer subgroup

\section{Shear bond strength test}

\section{Tooth preparation to receive ceramic samples}

Fifteen molars were collected. The teeth were freshly extracted and free from caries, restorations or fracture. Teeth were ultrasonically cleaned from any debris and were stored in $0.1 \%$ thymol solution for 1 week, and then in saline at room temperature till use. ${ }^{(45,46)}$ A split cylindrical copper mold having $14 \mathrm{~mm}$ internal diameter and a ring, , was filled with self-curing acrylic resin (Meliodent, BayerDental Ltd, Newbury, UK). Then roots of each tooth were inserted into the center of the metal mold till covering the furcation area and below the CEJ by $2 \mathrm{~mm}$. ${ }^{(36)}$ The excess of the acrylic resin was rapidly removed with metallic wax carver. After, complete polymerization of the acrylic resin, the split cylindrical copper mold and ring were disassembled and the acrylic block with the tooth embedded in it was removed.

The resin molds were horizontally placed on a dental surveyor (Paraskop, Bego, Bremen, Germany). It was attached to it by a sticky wax. The dental surveyor carbon rod marked on the coronal surface of the tooth to achieve horizontal plane on cutting the tooth. Three millimeters of the occlusal surfaces of the teeth were trimmed off with a dental trimmer (Omec muggio, Milano, Italy). Dentine surfaces were checked for absence of enamel and / or pulp tissue. Then, for each group, a new stone was used to remove the outer enamel, so that the outer surface is composed only of dentine. 


\section{Cementation procedures for the shear bond strength test samples}

For the three types of glass ionomer cements used in this study (GIC, NSGIC, NGGIC), the mixing ratio between powder and liquid was 1:1 as recommended by the manufacturer. The dentine surfaces of the tested samples were cleaned softly by cotton. Then, the dentine surface was conditioned with liquid of the glass ionomer for 30 seconds and rinsed using air/water spray for 15 seconds. Finally it was air dried, leaving the dentine surface visibly moist. $^{(47)}$

The IPS e.max CAD samples were etched as recommended by the manufacturer using $5 \%$ hydrofluoric acid (e.g. IPS Ceramic Etching Gel)) for 20 seconds, rinsed with water for 15 seconds. The mixed cement was applied on the etched ceramic surface and finally seated on the teeth. The excess cement was removed with sharp scaler. For standardizing the cementation procedure, the cemented samples were placed in a loading device (Rimac Spring Tester, Rimac Tools, N.J., USA) to a total axial seating force of $5 \mathrm{~kg}$ for 5 minutes. ${ }^{(48)}$ Then, a protective varnish (Cervitec. Ivoclar Vivadent AG, Schaan, Liechtenstein) was applied.

After storage period of 24 hours in distilled water, all the samples were subjected to thermocycling in a thermocycling machine (Proto-tech, Portland, Ore., USA) for 5000 cycles in water baths at 5 and $55^{\circ} \mathrm{C}$ with 30 seconds dwell time. ${ }^{(39)}$

\section{Shear bond strength test}

A universal testing machine (Lloyd Instruments, Segenswath West, Fareham, UK) was used. The shear bond strength was determined by compressive mode of force applied at the dentin-ceramic interface by the aid of a beveled metallic chisel attached to the upper movable compartment of the testing machine traveling at cross-head speed of $0.5 \mathrm{~mm} / \mathrm{min}$. The samples were tightened in a metal holder in the lower compartment of the testing machine. The load

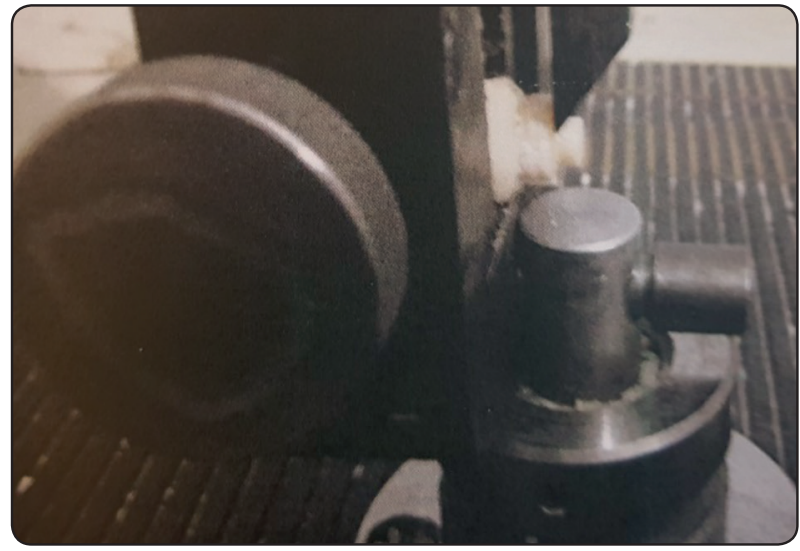

Fig (1): A sample tightened in a metal holder in a universal testing machine.

required for de-bonding was recorded in Newton. A shear load was applied until failure occurred. Using a computer software (Nexygen_MT, (Lloyd Instruments, Segenswath West, Fareham, UK), the shear bond strength was measured.

All data obtained in this research were calculated, tabulated and statistically analyzed.

A one-way ANOVA test followed by a Tukey test was performed to determine significant differences between the tested groups using a confidence level of $0.05(\mathrm{p}<0.05)$

\section{RESULTS}

\section{Colour test}

The CIE colour parameters were calculated from spectral reflectance measurements on a scanning spectrophotometer. Colour difference $(\Delta \mathrm{E})$ of the tested samples were calculated and represented in table (1) and figure (2). The highest delta $E(\Delta E)$ values were recorded for nano-silver (NSGIC) subgroup (2.6) while the least $\Delta \mathrm{E}$ values were recorded for the nano-gold (NGGIC) subgroup (2.3). All the recorded $\Delta \mathrm{E}$ values were not perceptible $(\Delta \mathrm{E}<3.7 \text { units })^{(30)}$. 


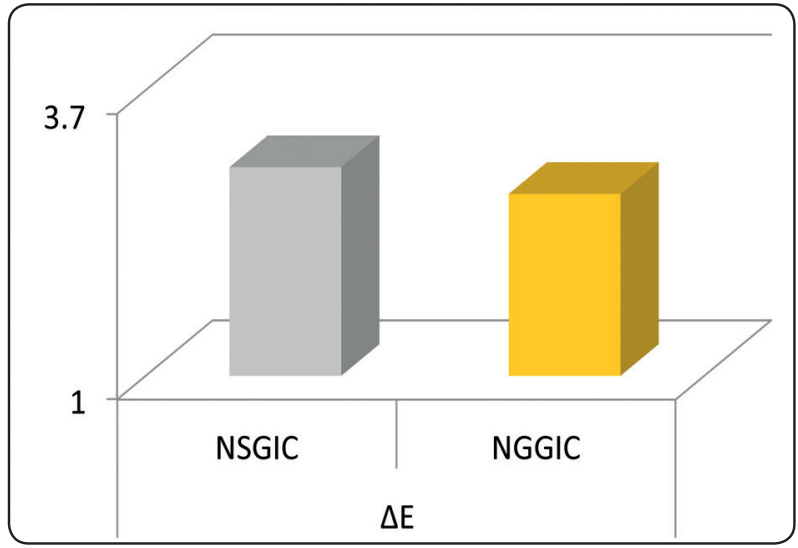

Fig. (2) Comparison between nanoparticle glass ionomer

TABLE (1) Delta E between the tested nanoparticle glass ionomer

\begin{tabular}{|l|c|c|}
\hline Subgroups & $\begin{array}{c}\text { Nano silver } \\
\text { (NSGIC) }\end{array}$ & Nano gold (NGGIC) \\
\hline$\Delta$ E Values & $2.6^{\mathrm{a}}$ & $2.3^{\mathrm{a}}$ \\
\hline S.D. & $(0.6)$ & $(0.5)$ \\
\hline
\end{tabular}

Same letter denotes no statistical significant difference

\section{Shear bond strength}

Means and standard deviations of the shear bond strength values for the tested groups are presented in table (2). A one way ANOVA Test (table 3) was used to determine significant differences between the tested groups $(\mathrm{p}<0.05)$. Tukey test for multiple comparisons of means at $(\mathrm{p}<0.05)$ was done following the one-way analysis of variance. Results showed that the control group (GIC) recorded the highest values (5.83 MPa) followed by the NGGIC subgroup (5.56 MPa) and the least values for the NSGIC subgroup (5.51 MPa). Statistical analysis showed no statistical significant difference between the control group and the 2 tested subgroups.

The three tested groups showed adhesivecohesive failure

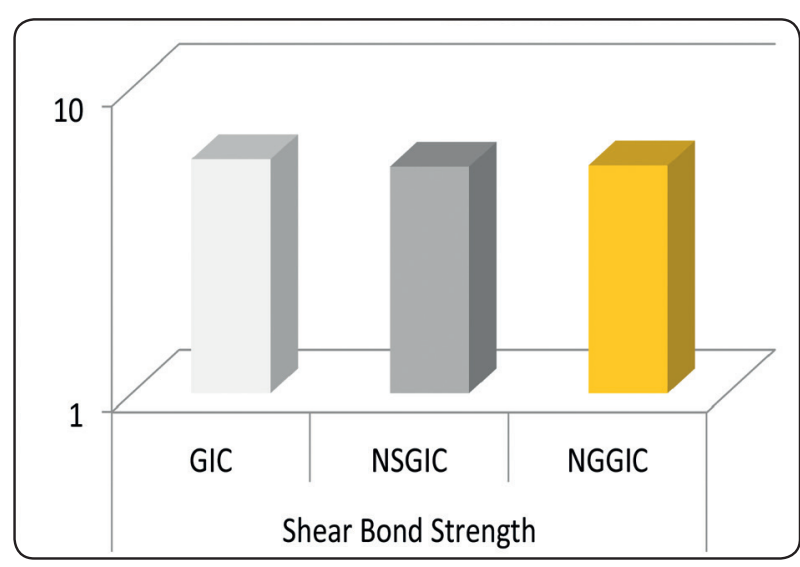

Fig (3) Comparison between shear bond strength of the tested glass ionomer cements

TABLE (2) Means and standard deviations of the shear bond strength of the tested groups (MPa)

\begin{tabular}{|l|c|c|c|c|}
\hline Type of GIC & GIC & NSGIC & NGGIC & $\begin{array}{c}\text { Critical } \\
\text { value }\end{array}$ \\
\hline $\begin{array}{l}\text { Shear bond } \\
\text { strength }\end{array}$ & $5.83^{\mathrm{a}}$ & $5.52^{\mathrm{a}}$ & $5.56^{\mathrm{a}}$ & \multirow{2}{*}{0.41} \\
\hline $\begin{array}{l}\text { Standard } \\
\text { deviations }\end{array}$ & $(0.14)$ & $(0.15)$ & $(0.15)$ & \\
\hline
\end{tabular}

Same letter denotes no statistical significant difference

TABLE (3) Analysis of variance between and within different groups due to shear bond strength test

\begin{tabular}{|l|c|c|c|c|c|}
\hline $\begin{array}{l}\text { Source of } \\
\text { Variation }\end{array}$ & $\begin{array}{c}\text { Sum of } \\
\text { Squares }\end{array}$ & $\begin{array}{c}\text { Degree of } \\
\text { Freedom }\end{array}$ & $\begin{array}{c}\text { Means } \\
\text { Squares }\end{array}$ & $\begin{array}{c}\text { F. } \\
\text { Ratio }\end{array}$ & $\begin{array}{c}\text { Significance } \\
\mathrm{P}\end{array}$ \\
\hline Total & 0.722 & 14 & ------ & ----- & ------- \\
\hline $\begin{array}{l}\text { Between } \\
\text { Groups }\end{array}$ & 0.2963 & 2 & 0.1482 & 4.1746 & $<.05$ \\
\hline $\begin{array}{l}\text { Within } \\
\text { Groups }\end{array}$ & 0.4257 & 12 & 0.0355 & ------ & ------ \\
\hline
\end{tabular}




\section{DISCUSSION}

The effect of nanoparticles addition to glass ionomer cement on the colour and bond strength was studied. Two types of nanoparticles were tested; silver nano-particles and gold nano-particles. IPS e.max CAD ceramic blocks were used. Christensen (2014), ${ }^{(40)}$ reported that when using lithium disilicate crowns, in case of adequately retentive tooth preparation with nearly parallel long axial walls, luting cements like glass ionomer and modified glass ionomer are indicated. Also, the manufacturer recommended the use of glass ionomer cement Vivaglass CEM for conventional cementation of the high strength lithium disilicate ceramic IPS e.max $\mathrm{CAD}$, if adequate retention is present.

The addition of nanoparticles in glass ionomer was investigated by many investigators. ${ }^{(15,33-36)}$ They tested the biological properties (antibacterial effect), the physical properties as well as the mechanical properties, ${ }^{(49)}$ Dental literature lacks information about the effect of addition of nanoparticles on the final cement colour. In some investigations shear bond strength was tested without the final restorations, which is not the case in this current investigation to try to simulate clinical conditions.

Daugela et al (2008), ${ }^{(50)}$ drew the attention that the bacteria may still be present on the walls of the prepared tooth to receive fixed restorations or gain access to the cavity if there is microleakage present after cementation. They concluded that an antibacterial activity of dental luting cements is a very important property when luting fixed restorations. Furthermore, Elkassas et al (2014), ${ }^{(51)}$ pointed out that the bacteria may survive underneath the restorations up till 139 days producing toxins and other destructive products of their metabolism. Thus the treatment efficacy to have free-microorganism environment depends to some extent on the antibacterial property of the luting agent used.

Releasing fluoride gives glass ionomers a cariostatic property; suppressing caries formation as well as an antibacterial potential. ${ }^{(52-54)}$ Silver and gold nanoparticles (AgNPs) and (AuNPs) were used to modify glass ionomer. The nano-sized particles are useful; as the smaller the particles are the higher specific surface areas. Thus particle are more efficient at a lower concentration. ${ }^{(55)}$

Silver nanoparticles (AgNPs) are recommended to be used as a broad-spectrum antimicrobial in medical and dental fields. This effect can be achieved at very low concentrations. So it does not enhance the development of resistant bacterial strains. ${ }^{(56,57)}$ AgNPs particles disrupt the mitochondrial respiratory chain and interrupt adenosine triphosphate synthesis, which, in turn, results in DNA damage. ${ }^{(58)}$ This property may play an important role in the suppression of the recurrent caries development. In cooperation with fluoride, silver nanoparticles induct the fluoroapatite synthesis. Some researchers ${ }^{(13,14,56,59-61)}$ reported that AgNPs may also enhance the bond strength to dentin as well as other physical properties.

Gold nanoparticles (AuNPs) were also tested in this study. AuNPs has an antibacterial effect which takes place in 2 steps. At first, they change the membrane potential and reduce the adenosine triphosphate synthase activities, leading to reduction of metabolism. Secondly, decline the ribosome subunit for the RNA binding, causing the biological mechanism to collapse. Also, AuNPs size and surface area produce some electronic effects enhancing the surface reactivity of nanoparticles. The higher surface area inyeracting with microorganisms the more improved contact with bacteria. ${ }^{(15)}$

Achieving optimal colour-matching between the ceramic restoration and the adjacent natural teeth is an important goal in the success of a fixed restoration. Replicating the natural appearance of tooth structure by a restoration requires careful control of its colour, translucency form and surface texture, as well as the shade of the used cement. The final shade may be affected by ceramic thickness and shade together as well as the luting agent and the colour of the underlying dental structure. The ceramic used in this current investigation, is an optical mixture of a 
glass matrix and lithium disilicate crystalline phase. It allows the light to pass through the material and reflect the background colour. In this present study, composite discs were used instead of dentin for the colour test to omit the variation of dentin shade colour. The colour of the composite used in this study was A2 as used by Koutayas \& Charisis (2008) $^{(42)}$ who used a control background $2 \mathrm{M} 2$, they reported that $2 \mathrm{M} 2$ colour shade corresponds to $26 \%$ of human teeth and represents an esthetically pleasing average colour for prostheses. According to Vita conversion chart 2M2 corresponds to A2. Al BenAli et al (2014) ${ }^{(62)}$ reported the significant effect of the background on lithium disilicate ceramic. Chaiyabutr et al (2011) ${ }^{(30)}$ studied the effect of the abutment tooth colour, cement colour, and ceramic thickness on the optical colour of the CAD/CAM lithium disilicate glass ceramic crown. They found a significant effect of the three parameters on the $\Delta \mathrm{E}$ values. Additionally, the influence of these parameters was found to significantly differ. When the crowns were cemented using opaque cement, the $\Delta \mathrm{E}$ values slightly decreased. Nakamura et al (2002) $)^{(21)}$ stated that the abutment impacts the ceramic colour when the ceramic thickness is less than $1.6 \mathrm{~mm}$, while other studies have suggested that the ceramic thickness should be at least $2.0 \mathrm{~mm}$ to moderate the effect of the abutment tooth on the overall colour. In this study, a thickness of $1.5 \mathrm{~mm}$ was used as recommended by the manufacturer in case of posterior crowns.

In this study IPS e-max CAD LT block was used. The low translucent ceramic was used as it was reported by the manufacturer that their low translucency was similar to that of natural dentin. Also, Al BenAli et al (2014) ${ }^{(62)}$ drew the attention that the lowest $\Delta \mathrm{E}$ values were observed with low translucent lithium disilicate ceramic using different background shades. So in this research, a standardized composite background of shade $2 \mathrm{M} 2$ was used. This shade as mentioned by many investigators ${ }^{(63,64)}$ corresponds to the middle third of a natural non discoloured tooth.
The selection of Vivaglass Cem in this study was used due to its recommendation by the manufacturer to be used with lithium disilicate e.max CAD due to its high translucency and natural looking with excellent optical properties enhancing the esthetic characteristics of all-ceramic restorations. The manufacturer also claims that the results in terms of esthetics are comparable to those achieved in the adhesive cementation of all-ceramic restorations.

Colour measuring devices such as spectrophotometers and colourimeters have become popular since they offer accuracy, standardization and numerical colour expression. A visible-range spectrophotometer (Vita Easy shade Advance 4.0) was used to measure the colour in the present study. It uses a continuous light source over the full visible and near infrared spectrums and a colour temperature of $3,350^{\circ} \mathrm{K}$. The handpiece of the spectrophotometer contains an outer ring of 19 fiber optics $1 \mathrm{~mm}$ in diameter, used to illuminate the samples and three different spectrometers: one spectrometer monitors the light source output during the calibration and measurement process, and two analyze the internally scattered light at different depths using special receiver elements.

All samples undergone thermal cycling to simulate clinical conditions Thermo-cycling is considered to be a clinically relevant aging parameter.

Since natural tooth structure transfers external biting loads through enamel into dentin as compression forces. These forces spread over a large internal volume resulting in lower local stresses. Whereas a tooth with a restoration or filling, reacts to stress much differently than; a natural intact tooth. Any force on the restoration produces a complex stress distribution; a mixture of compressive, tensile, and shear stresses along the tooth/ restoration interface. Since the process of mastication is basically related to shearing or cutting away, the true nature of adhesive strength of the materials at the interface is reflected by the shear bond strength. ${ }^{(65)}$ 
Shear bond strength (SBS) test was performed to evaluate the effect of modifying glass ionomer cement with nanoparticles on the bond strength of lithium disilicate ceramics. SBS was investigated in a universal testing machine at a crosshead speed of $1 \mathrm{~mm} / \mathrm{min}$. A shear load was applied until failure occurred.

The dentine surface was conditioned with using the liquid of the glass ionomer for $30 \mathrm{sec}$., then, rinsed with water for $15 \mathrm{sec}$. The IPs e.max CAD ceramic was etched as recommended by the manufacturer in case of using glass ionomer, this may cause increase of surface roughness and surface area.

In regards to colour, the results showed that the two tested types of glass ionomer in comparison with the commercial glass ionomer cement, gave rise to a $\Delta \mathrm{E}$ values in the range of clinical acceptability. $\Delta \mathrm{E}$ values smaller than 3.7 were considered, clinically accepted. Due to the fact that both the ceramic and the composite substructure were constant, any variation would be from the glass ionomer cement used. This may be due to the small percentage and size of the nanoparticles used. Although no clinical variations were recorded, the group (NSGIC) resulted in slight darker colour than the other 2 groups. This may be due to the silver nano-particles. This comes in accordance with El-Wassefy et al (2017). ${ }^{(33)}$

The results of the shear bond strength test, showed a slight decrease in SBS for the experimental groups (NSGIC) \& (NGGIC) than the control group (GIC). Yet, there was no statistical significant difference between the different tested groups. This indicates that the modification of glass ionomer cement with nanoparticles did not affect their bond strength. These results were in agreement with both Porenczuk et al (2016) ${ }^{(34)}$ as well as AbdelHakeem AMI (2017) ${ }^{(35)}$ who reported no impact of nano-particles addition to glass ionomer cement as regard bond strength to dentine. The insignificant difference in mechanical properties of NGGIC and NSGIC may be due to that nano particles may act as a filler forming obstacles for crack growth. Nanoparticles can occupy the empty spaces between the larger glass particles and act as additional bond- ing sites for the poly-acrylic polymer. ${ }^{(66)}$ Also, ElWassefy et al (2017), ${ }^{(33)}$ attributed the insignificant effect of nanoparticles on glass ionomer mechanical properties to the physical addition of nanoparticles to the cement without interfering matrix setting reaction. Also, their nano-size allows their dispersion between and around polymer chains.

From the obtained results, The hypothesis was rejected as both types of nano-particles when added to glass ionomer cement, did not had any significant impact upon neither the final colour of the restoration nor the shear bond strength.

\section{CONCLUSIONS}

Within the limitations of this study and based on the obtained results, the following can be concluded:

1- As regards colour, modified glass ionomer cement resulted in a $\Delta \mathrm{E}$ within the clinical acceptance.

2- Modified glass ionomer cement with nanoparticles did not significantly affect the shear bond strength.

3- The addition of gold nanoparticles to glass ionomer showed less $\Delta \mathrm{E}$ compared to nonmodified glass ionomer, than does the addition of silver nanoparticles.

4- The two types of nanoparticles used in this study showed both near effect on the glass ionomer cement concerning both shear bond strength and colour.

\section{REFERENCES}

1. Flury S, Schmidt SZ, Peutzfeld A, Lussi A. Dentin bond strength of two resin-ceramic computer-aided design/ computer-aided manufacturing (CAD/CAM) materials and five cements after six months storage. Dent Mater 2016; 35(5): 728-735.

2. Siqueira F / Cardenas AM / Gutierrez MF / Malaquias P / Hass V / Alessandra Reis A / Loguercio AD / Jorge Perdigao J. Laboratory Performance of Universal Adhesive Systems for Luting CAD/CAM Restorative Materials. J Adhes Dent 2016; 18: 331-340. 
3. Porto T S, Renato Cassio Roperto R C, Akkus A, Akkus O, Teich S, Faddoul F, Porto-Neto S T, Campos E A. Effect of storage and aging conditions on the flexural strength and flexural modulus of CAD/CAM materials. Dent Mater J 2018-111. Published: January 30, 2019 [Advance publication] Released: December 11, 2018

4. Bähr N, Keul C, Edelhoff D, Eichberger M, Roos M, Gernet W, et al. Effect of different adhesives combined with two resin composite cements on shear bond strength to polymeric CAD/CAM materials. Dent Mater J. 2013; 32:492-501.

5. Shashirekha G, Jena A, Hegde J. Bond strength of light activated glass ionomer with different conditioners on human dentin. Int J Sci Technol Res 2012; 1:26-29.

6. O'Brien WJ: Dental Materials and Their Selection, Chicago: Quintessence Publishing, 1997; 2nd ed.

7. Rosensteil SF, et al. Dental luting agents: a review of the current literature. J Prosthet Dent. 1998; 80: 280.

8. Dewald P and Arcoria J. "Evaluation of glass Cement cores under cast crowns”. Dent Mater. 1990; 6(2): 129-132.

9. Anand C and Bhagwat SV. Antibacterial effects of glass ionomers on carious dentin-An in vivo study. J Conserv Dent. 2000; 3(2): 65-74.

10. Cattani- Lorente MA, Dupis V, Moya F, Payan J, Meryer JM. Comparative study of the physical properties of a polyacid modified composite resin-modified glass ionomer cement.Dent. Mater 1999; 15(1):21-32.

11. Zaho J, Xie D. A novel hyperbranched poly (acrylic acid) for improved resin-modified glass ionomer restoratives. Dent Mater.2011; 27(5):478-486.

12. Agrawal P, Mehta K, Vashisth P, Bhat P, Goutham Vishnu BV. Green synthesis of silver nanoparticles and their application in dental filling material. Int. J. innovative res. sci, eng. technol. 2014; 3(6): 13038- 13052.

13. Monteiro DR, Gorup LF, Takamiya AS, Ruvollo-Filho AC, de Camargo ER, Barbosa DB. The growing importance of materials that prevent microbial adhesion: antimicrobial effect of medical devices containing silver. Int J Antimicrob Agents. 2009; 34:103-110.

14. Allaker RP. The use of nanoparticles to control oral biofilm formation. J Dent Res. 2010; 89:1175-1186.

15. Shamaila S, Zafar N, Riaz S, Sharif R, Nazir J, Naseem S. Gold nanoparticles: An efficient antimicrobial agent against enteric bacterial human pathogen. Nanomaterials. 2016; 6(4): 71-80.

16. Southan D. Factors affecting the translucency of dental porcelain. Quintessence Int 1987; 18:197-202.

17. Ferro KJ, Editor and Chairman, Morgano SM, Driscoll CF, Freilich MA, Albert D. Guckes AD, Knoernschild KL, McGarry TJ. The glossary of prosthodontic terms. The academy of prosthodontics. J Prosthet Dent 1994; 71:41-112.

18. Douglas RD, Przybylska M. Predicting porcelain thickness required for dental shade matches. J Prosthet Dent. 1999; 82:143-149.

19. Deany IL: Recent advances in ceramics for dentistry. Crit Rev Oral Biol Med 1996; 7:134-143.

20. Holloway JA, Miller RB: The effect of core translucency on the aesthetics of all-ceramic restorations. Pract Periodontics Aesthet Dent 1997; 9:567-574.

21. Nakamura T, Saito O, Fuyikawa J, et al: Influence of abutment substrate and ceramic thickness on the colour of heatpressed ceramic crowns. J Oral Rehabil 2002; 29:805-809.

22. Vichi A, Ferrari M, Davidson CL: Influence of ceramic and cement thickness on the masking of various types of opaque posts. J Prosthet Dent 2000; 83:412-417.

23. Koutayas SO, Kakaboura A, Hussein A, et al: Colorimetric evaluation of the influence of five different restorative materials on the color of veneered densely sintered alumina. J Esthet Restor Dent 2003; 15:353-360.

24. Falahchai SM, Zeghami S, Hemmati YB. Main factors affecting the final color of ceramic restorations. Adv Dent \& Oral Health. 2017; 5(3):555-661.

25. Stevenson B, Ibbetson R. The effect of the substructure on the colour of samples/restorations veneered with ceramic: a literature review. J Dent 2010; 38(5):361-368.

26. Kourtis SG, Tripodakis AP, Doukoudakis AA: Spectrophotometric evaluation of the optical influence of different metal alloys and porcelains in the metal-ceramic complex. J Prosthet Dent 2004; 92:477- 485.

27. Jalali H, Alizadeh ES Sadighour L, Shabestarigo GO, Fard MJ. The effect of background and ceramic thickness on the color of an all-ceramic restorative system. J Calif. Dent Assoc. 2010; 38(3):179-186.

28. Chu FC, Chow TW, Chai J: Contrast ratios and masking ability of three types of ceramic veneers. J Prosthet Dent 2007; 98: 359-364. 
29. Li Q. Yu H, Wang YN: Spectrophotometric evaluation of the optical influence of core build-up composites on allceramic materials. Dent Mater 2009; 25:158-165.

30. Chaiyabutr Y, Kois JC, Lebeau D, et al: Effect of abutment tooth color, cement color, and ceramic thickness on the resulting optical color of a CAD/CAM glass-ceramic lithium disilicate-reinforced crown. J Prosthet Dent 2011; 105:83-90.

31. Azer SS, Rosenstiel SF, Seghi RR, et al: Effect of substrate shades on the color of ceramic laminate veneers. J Prosthet Dent 2011; 106:179-183

32. Dozi'c A, Kleverlaan CJ, Meegdes M, et al: The influence of porcelain layer thickness on the final shade of ceramic restorations. J Prosthet Dent 2003; 90:563-570.

33. El-Wassefy NA, El-Mahdy RH. El-Kholany NR. The impact of silver nanoparticles integration on biofilm formation and mechanical properties of glass ionomer cement. $\mathrm{J}$ Esthet Restor Dent. 2018; 30(2):146-152.

34. Porenczuk A, Firlej P, Szczepańska G, Kolenda A, OlczakKowalczyk D. The laboratory comparison of shear bond strength and microscopic assessment of failure modes for a glass-ionomer cement and dentin bonding systems combined with silver nanoparticles. Acta of Bioengineering and Biomechanics. 2016; 18(2): 59-70.

35. Abdel-Hakeem AMI. Evaluation of an experimental glass ionomer cement modified by colloidal gold and silver:An in vitro study. Thesis of Doctor degree. Minia University. 2017.

36. Mohsen C A, Abu-Eittah M R, Hashem R M M. The antibacterial and antifungal effect of Silver Nanoparticles and silver hydroxyapatite nanoparticles on Dental Ceramic. Report and Opinion 2015; 7(7): 83-88.

37. Botelho MG. Compressive strength of glass ionomer cements with dental antibacterial agents. SADJ. 2004; 59(2):51-53.

38. Rosenstiel SF, Land MF, Crispin BJ. Dental luting agents: a review of the current literature. J Prosthet Dent. 1998; 80(3):280-301.

39. Ozcan M, Vallittu PK. Effect of surface conditioning methods on the bond strength of luting cements to ceramics. Dent Mater. 2003; 19: 725-731.

40. Christensen GJ. Use of luting or bonding with lithium disilicate and zirconia ceramics, JADA 2014; 145(4): 383386.
41. Christensen GJ. CR Foundation. Endo access through ceramics: are cracks a problem? Clinicians Rep. 2012; 5(10):1-3.

42. Koutayas S and Charisis D. Influence of the core material and the glass infiltration mode on the color of glassinfiltrated ceramic veneers over discolored backgrounds. A spectrophotometric evaluation. Eur J Esthet Dent. 2008; 3(2):160-173.

43. Gomes AL, Ramos JC, del Riego SS, Montero J, Albaladejo A. Thermocycling effect on microshear bond strength to zirconia ceramic using Er:YAG and tribochemical silica coating as surface conditioning. Lasers Med. Sci. 2015; 30: 787-795

44. Chu SJ, Devigus A, Mieleszko AJ: Fundamentals of Color: Shade Matching and Communication in Esthetic Dentistry. Chicago, IL, Quintessence Pub. Co., 2010; $2^{\text {nd }}$ ed.

45. Montes MA, De Goes MF, Sinhoreti MA. The in vitro morphological effects of some current pre-treatments on dentin surface: A SEM evaluation. Oper Dent 2005; 30:201-12.

46. Nikaido T, Takano Y, Sasafuchi Y, Burrow MF, Tagami J. Bond strengths to endodontically-treated teeth. Am J Dent 1999; 12:177-80.

47. Rai N, Naik R, Ravi Gupta R, Shetty S, Singh A. Evaluating the Effect of Different Conditioning Agents on the Shear Bond Strength of Resin-Modified Glass Ionomers. Contemp Clin Dent. 2017; 8 (4): 604-612.

48. Ozyoney G, Yanikoglu F, Ozyoney N, Oksuz M. Shear bond strength of composite resin cements to ceramics. J Marmara Univ Dent Fac. 2013; 2(6): 61-66.

49. Paiva L, Fidalgod T.K.S., da Costa L.P. , Maia L.C. ,Balan L,.Anselme K., Ploux L, Thiréc R.M.S.M. Antibacterial properties and compressive strength of new one-step preparation silver nanoparticles in glass ionomer cements (NanoAg-GIC). J Dent.2018; 69:102-109.

50. Daugela P, Oziunas R, Zekonis G. Antibacterial potential of contemporary dental luting cements. Stomatologija. 2008; 10 (1):16-21.

51. ElKassas D.W., Fawzi E.M., EL Zohairy A., The effect of cavity disinfectants on the micro-shear bond strength of dentin adhesives, Eur. J. Dent., 2014; 8: 184-190.

52. Lyapina MG, Tzekova M, Dencheva M, Krasteva A, Yaneva-Deliverska M, Kisselova A. Nano-Glass-Ionomer Cements In Modern restorative Dentistry. $\mathrm{J}$ of IMAB. 2016; 22 (2): 1160-1165. 
53. Xie D, Weng Y, Guo X, et al. Preparation and evaluation of a novel glass-ionomer cement with antibacterial functions. Dent Mater. 2011;27(5):487-496.

54. Tenuta LMA, Ribeiro CCC, de Valor Gonçalves NC, et al. The short term in situ model to evaluate the anticariogenic potential of ionomeric materials. J Dent. 2005; 33(6):491- 497.

55. Li F, Weir MD, Chen J, Xu HH. Comparison of quaternary ammonium-containing with nano-silver-containing adhesive in antibacterial properties and cytotoxicity. Dent Mater. 2013; 29: 450- 461.

56. Morones JR, Elechiguerra JL, Camacho A, Holt K, Kouri JB, Ramírez JT, et al. The bactericidal effect of silver nanoparticles. Nanotech. 2005; 16:2346-2353.

57. Zhang K, Cheng L, Imazato S, Antonucci JM, Lin NJ, LinGibson S, et al. Effects of dual antibacterial agents MDPB and nano-silver in primer on microcosm biofilm, cytotoxicity and dentine bond properties. J Dent. 2013; 41:464- 474.

58. AshaRani PV, Low KahMun G, Hande MP, Valiyaveettil S. Cytotoxicity and genotoxicityof silver nanoparticles in human cells. ACS Nano. 2009; 3:279-90.

59. Gong P, Li H, He X, Wang K, Hu J, S WT. Preparation and antibacterial activity of Fe3O4@Ag nanoparticles. Nanotech.2007; 18 (28): 285604: 285611.
60. Corrêa JM., et al. Silver Nanoparticles in Dental Biomaterials. Int J Biomater. 2015; Article ID 485275, 9P.

61. Galler K., Hiller K.A., Ettl T., Schmalz G., Selective influence of dentin thickness upon cytotoxicity of dentin contacting materials, J. Endod. 2005; 31:396-399.

62. Al Ben Ali AA., Kang K, Finkelman MD, Zandparsa R, Hirayama H. The Effect of Variations in Translucency and Background on Color Differences in CAD/ CAM Lithium Disilicate Glass Ceramics. J.Prosthodo nt.2014;(23):213-220.

63. Culpepper W. A comparative study of shade matching procedures. J Prosthet Dent 1970; 24:166-173.

64. Van der Burgt TP, Ten Bosch JJ, Borsboom PCF, Kortsmit WJ. A comparison of new and conventional methods for quantification of tooth color. J Prosthet Dent 1990; 63:155-162.

65. Nujella BP, Choudary MT, Reddy SP, Kumar MK, Gopal T. Comparison of shear bond strength of aesthetic restorative materials. Contemp Clin Dent 2012; 3:22-26.

66. Dadkana S, Salaria S, Khakbiza M, M Ataib. Mechanical properties of dental adhesives containing gold nanoparticles. Proceedings of 5th. International Congress of Nanoscience and Nano Technolology. Tehran Iran 2014; 1-3. 